Article

\title{
Development of Resilience Index Based on Flooding Damage in Urban Areas
}

\author{
Eui Hoon Lee ${ }^{1}$ and Joong Hoon Kim $^{2, *}$ \\ 1 Research Center for Disaster Prevention Science and Technology, Korea University, Seoul 02841, Korea; \\ hydrohydro@naver.com \\ 2 School of Civil, Environmental and Architectural Engineering, Korea University, Seoul 02841, Korea \\ * Correspondence: jaykim@korea.ac.kr; Tel.: +82-02-3290-3316
}

Received: 10 April 2017; Accepted: 9 June 2017; Published: 13 June 2017

\begin{abstract}
Flooding volume in urban areas is not linearly proportional to flooding damage because, in some areas, no flooding damage occurs until the flooding depth reaches a certain point, whereas flooding damage occurs in other areas whenever flooding occurs. Flooding damage is different from flooding volume because each subarea has different components. A resilience index for urban drainage systems was developed based on flooding damage. In this study, the resilience index based on flooding damage in urban areas was applied to the Sintaein basin in Jeongup, Korea. The target watershed was divided into five subareas according to the status of land use in each subarea. The damage functions between flooding volume and flooding damage were calculated by multi-dimensional flood damage analysis. The extent of flooding damage per minute was determined from the results of flooding volume per minute using damage functions. The values of the resilience index based on flooding damages were distributed from 0.797292 to 0.933741 . The resilience index based on flooding damage suggested in this study can reflect changes in urban areas and can be used for the evaluation of flood control plans such as the installation, replacement, and rehabilitation of drainage facilities.
\end{abstract}

Keywords: flooding damage; resilience index; multi-dimensional flood damage analysis

\section{Introduction}

Heavy rainfall resulting from climate change can lead to inundation in urban areas; therefore, a proper evaluation of urban drainage systems is required. The proper evaluation of urban drainage systems is an important factor in the design and operation of urban drainage facilities. Many researchers have studied resilience in urban cities and drainage systems. In the 1990s, the concept of sustainability was introduced in urban cities and research on developing sustainable urban development models was conducted [1]. The role of urban parks in a sustainable city and the meanings, models, and metaphors of resilient cities for various factors such as sporting, relax, being with children, meeting others, escaping from city, walking the dog, being in nature, meditating and getting inspiration were suggested $[2,3]$. A sustainable city model with global sustainability with global capital, city capacity and city condition was determined [4]. Risk and resilience were incorporated to enhance the sustainability of urban water systems using the concept of ecosystem resilience including potable water use, gross pollutants, cost and social acceptance [5]. The roles of risk, resilience, and environmentally sustainable cities were studied in order to frame national security and energy policies [6]. The concept of resilience was introduced based on these studies.

In the 2010s, a new concept of sustainability and resilience in urban systems was proposed. Sustainability and resilience with non-equilibrium, adaptive planning and design considering bus routes and urban drainage swales were applied in the new urban world [7]. Collaborative research in urban areas to quantify the cost-effectiveness of resilience and integrative flood management 
was announced [8]. A resilience-based design and a management paradigm for unpredictable and manmade catastrophic disasters was suggested as well as the concept of sustainable, robust, and resilient water distribution systems [9,10]. A conceptual framework for designing, planning, and managing resilient cities was constructed, considering climate change and environmental risk [11,12]. The integration of risk and resilience in engineering systems was adapted to manage natural and man-made catastrophes [13]. A conceptual framework with various factors such as climate change, rapid urbanization, and population growth was created for mitigation, adaptation, and coping strategies [14]. Resilience-based failure mode effects and a criticality analysis for regional water supply system were proposed [15]. Recently, various resilience studies on urban systems including various factors emerged.

Recently, resilience in urban drainage systems has been studied though research that focused on the resilience in urban cities and water distribution systems. A global analysis approach considering link failure, flood volume and flood duration was used to investigate structural resilience in urban drainage systems and resilient urban drainage as options for optimized area management $[16,17]$. A social-ecological index for measuring flood resilience and multifunctional urban flood resilience enhancement strategies were suggested [18,19]. A global analysis approach considering flood volume was used for the evaluation of functional resilience in urban drainage systems [20]. Cooperative operation of centralized and decentralized reservoirs was proposed for flood reduction and resilience about flooding volume in urban drainage systems [21]. Resilience studies applied to urban cities and drainage systems were introduced.

Resilience of urban area to flooding has also been studied. In urban drainage systems, the details of the flooding and the measures were conducted to mitigate such floods in the future [22]. Reflexivity, knowledge and adaptation were used for describing the potential urban form of a flood-resilient urban area [23]. A methodology of urban flooding resilience was aimed to be organized into a software tool the choice of vulnerability indicators and the integration of the point of view of various stakeholders [24]. Learning and action alliances for the integration of flood risk management into urban planning was suggested [25]. Urban flooding resilience was introduced as a key focus of flooding management [26].

The resilience of earlier research focused on the flood volume in urban drainage systems. Failure in urban drainage systems was defined as flooding or malfunctioning of urban drainage facilities [21]. A regional classification was required because flooding depth is not linked to flooding damage in some areas, but it is linked to flooding damage in other areas. In this study, multi-dimensional flood damage analysis (MD-FDA) was applied to divide the target area into several subareas according to the status of land use and to obtain regional damage functions between flooding volume and damage. The results of minutely flooding volume at each node by rainfall runoff simulation were obtained and were converted to minutely flooding damage. The resilience index for flooding damage was suggested and applied to the target area.

\section{Methodologies}

This study consists of six parts. The first part is application of MD-FDA for obtaining flooding damages at each subarea. The second part is obtaining damage functions based on relations between flooding volume and damage at each subarea. The third part is generation of synthetic rainfall data for rainfall runoff simulation. The fourth part is obtaining the results of minutely flooding volume by rainfall runoff simulations. The fifth part is conversion of flooding volume to flooding damage by damage functions. The last part is application of the results of flooding damage to resilience index. The flowchart for this study is shown in Figure 1. 


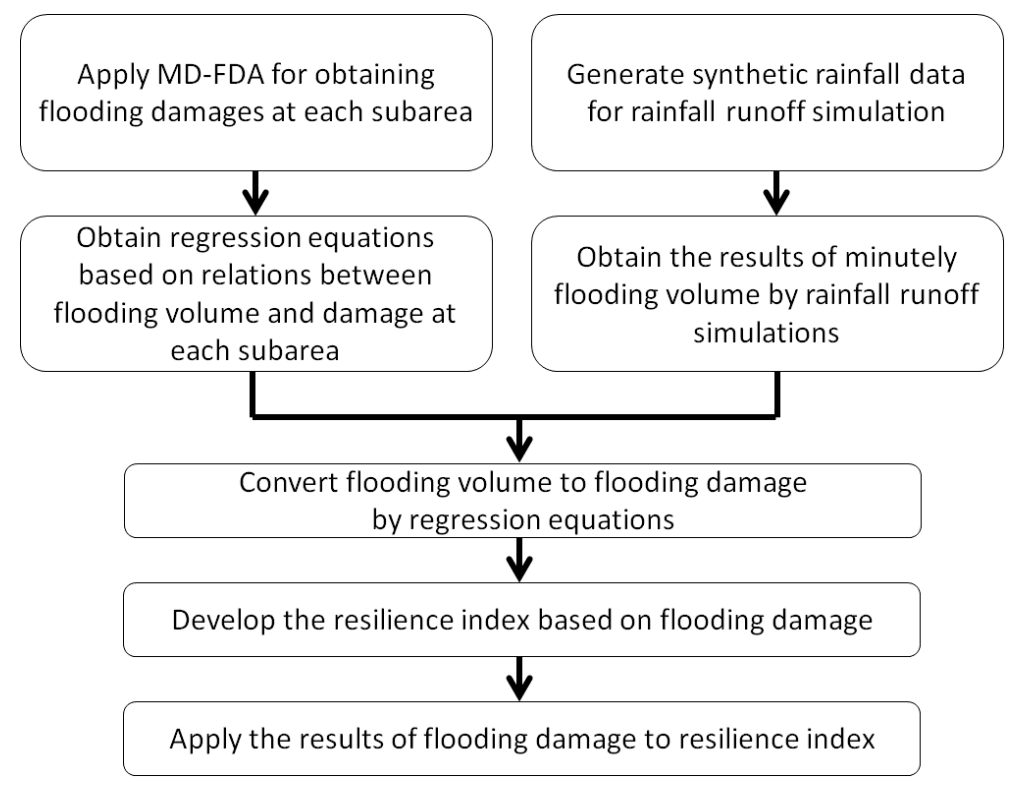

Figure 1. Resilience evaluation flowchart for this study.

\subsection{Multi-Dimensional Flood Damage Analysis}

The MD-FDA was developed for economic analysis in flood control projects [27]. It is based on the flooding depth determined by administrative districts. The components of the MD-FDA are damage to humans, building damage, damage to contents of buildings, farmland damage, crop damage, inventory damage, and public facility damage. The schematic of estimating flood damage by MD-FDA is shown in Figure 2.

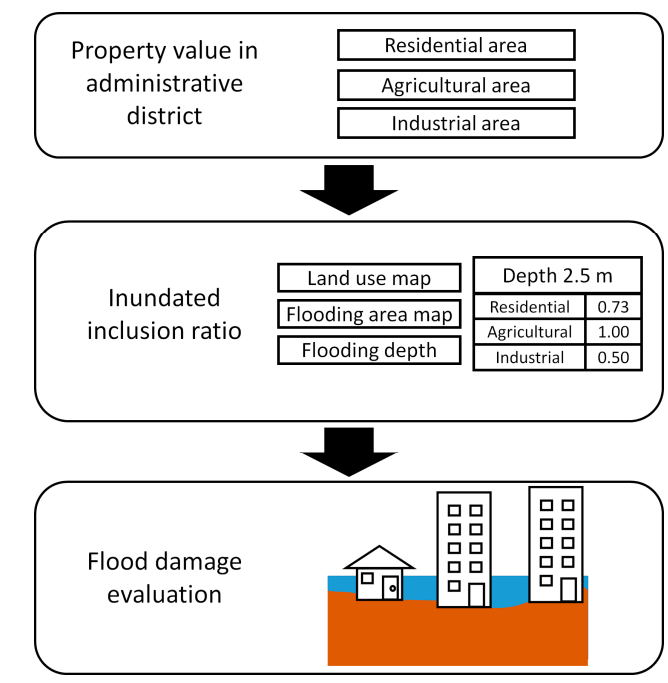

Figure 2. Schematic of estimating flood damages by multi-dimensional flood damage analysis (MD-FDA).

Damage types in MD-FDA are different from each other. In residential areas, the damage of buildings and the damage of contents of buildings are classified as structure and contents, respectively. In agricultural areas, the buried and lost areas of rice paddy fields and the damage of crops are categorized as farmland and crops, respectively. The industrial area covers tangible assets and inventories. Infrastructure represents flood-related damage of roads, bridges, railroads, and river 
structures. The person represents death and refugees. The MD-FDA requires flooding depth data, frequency of rainfall, and Geographic Information System (GIS) land use information. The value of flooding damage is obtained by calculating the property cost based on land use and the relevant portion of flooding depth and area. The ratio of damage to flooding depth in residences is shown in Table 1 [28].

Table 1. The ratio of damage by flooding depth in residences.

\begin{tabular}{cccccc}
\hline Depth $(\mathrm{m})$ & $\mathbf{0 ~ 0 . 5}$ & $\mathbf{0 . 5} 1.5$ & $\mathbf{1 . 5} 2.5$ & Over 2.5 & Comments \\
\hline $\begin{array}{c}\text { The ratio of damage in } \\
\text { detached houses (\%) }\end{array}$ & 15 & 40 & 83 & 100 & - \\
\hline $\begin{array}{c}\text { The ratio of damage in } \\
\text { apartments and buildings (\%) }\end{array}$ & $15 / \mathrm{n}$ & $40 / \mathrm{n}$ & $83 / \mathrm{n}$ & $100 / \mathrm{n}$ & $\begin{array}{c}\mathrm{n} \text { is the number of } \\
\text { floors }\end{array}$ \\
\hline
\end{tabular}

The ratio of damage by flooding depth in buildings is the same as it is in apartments. The ratio of damage by flooding depth in buildings in which the contents, tangible assets, and inventories are damaged is shown in Table 2 [28].

Table 2. The ratio of damage by flooding depth in contents of buildings.

\begin{tabular}{cccccc}
\hline Depth (m) & $\mathbf{0 \sim 0 . 5}$ & $\mathbf{0 . 5} \mathbf{1 . 0}$ & $\mathbf{1 . 0} \mathbf{2 . 0}$ & $\mathbf{2 . 0} \mathbf{3 . 0}$ & Over 3.0 \\
\hline $\begin{array}{c}\text { The ratio of damage in } \\
\text { contents of buildings (\%) }\end{array}$ & 14.5 & 32.6 & 50.8 & 92.8 & 100 \\
\hline $\begin{array}{c}\text { The ratio of damage in } \\
\text { tangible assets (\%) }\end{array}$ & 25 & 50 & 80 & 100 & 100 \\
\hline $\begin{array}{c}\text { The ratio of damage in } \\
\text { inventories (\%) }\end{array}$ & 15 & 30 & 60 & 100 & 100 \\
\hline
\end{tabular}

The values in Tables 1 and 2 represent the ratios of damage to flooding depth for each factor. The factors are houses, apartments, contents of buildings, tangible assets, and inventories. The data in Tables 1 and 2 are somewhat outdated and can be replaced if new data is uploaded. The property value of each factor is required to obtain the results of flooding damage. The ratio of damage by flooding depth in farmland, tangible assets, inventories and crops of agricultural area and industrial area is shown in Table 3 [28].

Table 3. The ratio of damage by flooding depth in crops.

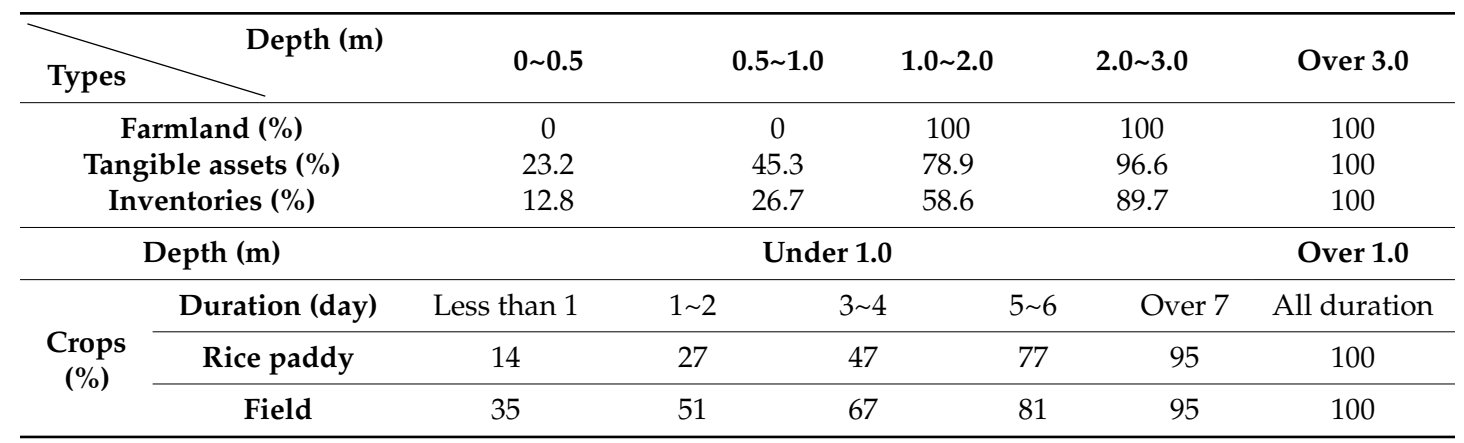

In agricultural area, the property value of farmlands consists of rice paddy and dry field. The price per area of rice paddy and dry field is based on the data of Korea Appraisal Board [29], and each 
buried area and dry field are priced differently. The property value of farmlands in agricultural area can be calculated by multiplying areas of rice paddy and dry field by assessment about price of the buried and lost areas. The property value of crops in agricultural area consists of types of crops, areas of rice paddy and dray field and consumer price index. The cost by types of crops is based on the production cost of agricultural products [29]. Areas of rice paddy and dry field are same as farmland. The consumer price index is also based on the data of Statistics Korea [29]. Table 4 shows the estimation of property values [27].

Table 4. Estimation of property values.

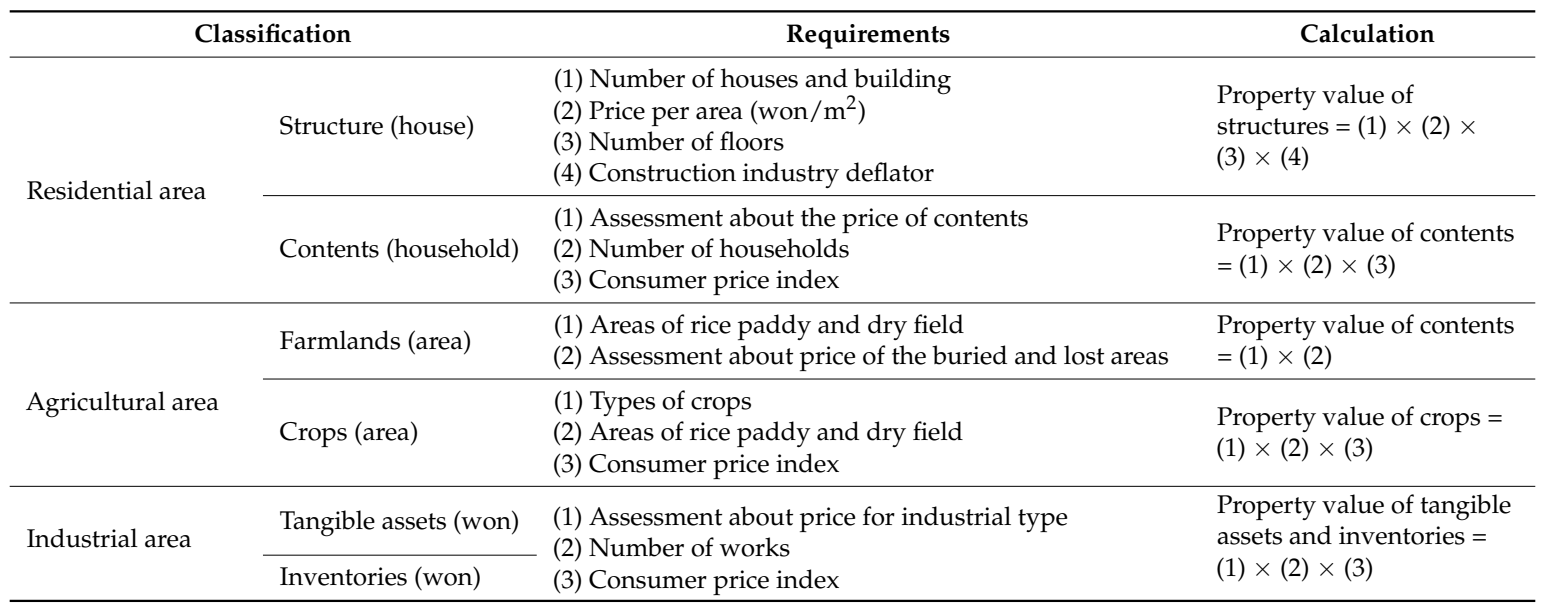

In industrial areas, the property value of tangible assets consists of assessment about price for industrial type, number of works and consumer price index. Assessment about price for industrial type is based on the data of Statistics Korea [29]. Consumer price index is also based on the data of Statistics Korea [29]. The property value of industrial area is calculated by assessment about price for industrial type, number of works and consumer price index.

Flooding volume and flooding depth obtained by Storm Water Management Model (SWMM) simulation and the results of property value calculated in Table 3 were used for the calculation of flooding damage. Flooding damage was calculated using Equation (1) [28]:

$$
F_{d}=P_{v} \times R_{a} \times R_{d},
$$

where $F_{d}$ is the flooding damage, $P_{v}$ is the property value, $R_{a}$ represents the ratio of flooding area, and $R_{d}$ is the ratio of damage to flooding depth.

\subsection{Generation of Synthetic Rainfall Data}

In this study, synthetic rainfall data was required for rainfall runoff simulations. The design of drainage facilities in urban drainage systems is based on the Huff distribution [30]. The Huff distribution includes four quartiles and each quartile has a different peak time. The damage functions of the Huff distribution for Jeongup, Korea are shown in Equations (2)-(5), respectively [31]:

$$
\begin{gathered}
y=30.417 x^{6}-95.785 x^{5}+113.87 x^{4}-62.09 x^{3}+13.469 x^{2}+1.1268 x-0.0019, \\
y=-30.678 x^{6}+93.204 x^{5}-101.35 x^{4}+43.908 x^{3}-4.5765 x^{2}+0.4869 x+0.0014, \\
y=36.029 x^{6}-98.986 x^{5}+95.279 x^{4}-38.622 x^{3}+7.4086 x^{2}-0.1088 x+0.0002, \\
y=-29.739 x^{6}+81.235 x^{5}-81.962 x^{4}+37.734 x^{3}-7.1157 x^{2}+0.8466 x-0.0001,
\end{gathered}
$$


where $y$ refers to the cumulative rainfall ratio and $x$ represents the cumulative time ratio. In Korea, including Jeongup, the third quartile of the Huff distribution was suggested as a proper rainfall distribution [32]. The process of generating synthetic rainfall data consists of three steps. The first step is the distribution of cumulative rainfall amount according to the rainfall duration. The second step is the acquisition of rainfall distribution according to the rainfall duration by using the results of the first step. The final step is to use the amount of rainfall amount and duration to generate synthetic rainfall data using the Huff distribution. The process of generating synthetic rainfall data using the Huff distribution is shown in Figure 3.

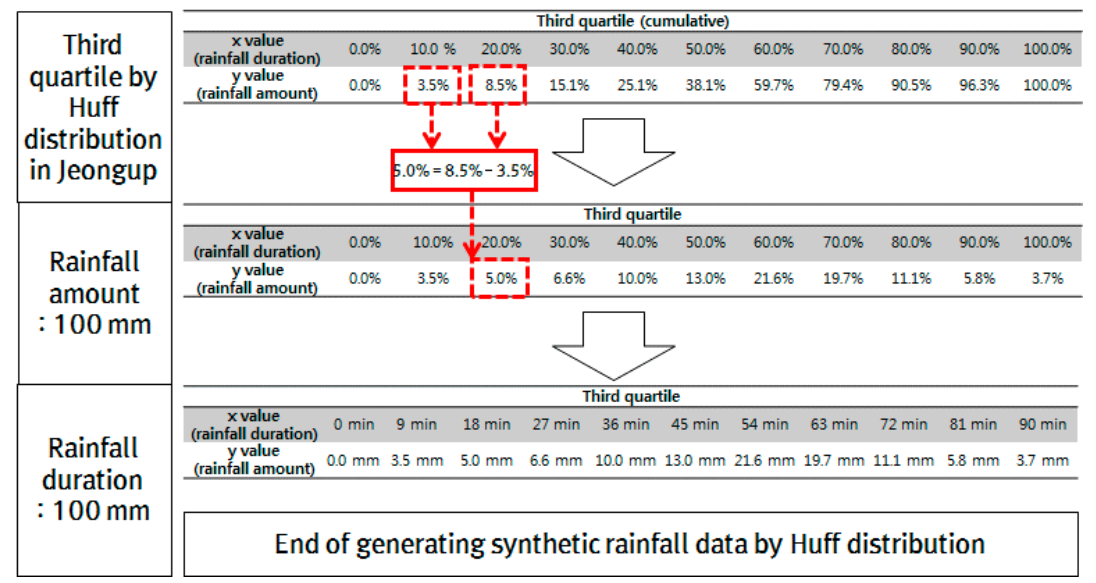

Figure 3. Generation of synthetic rainfall data by Huff distribution.

\subsection{Development of Resilience Index Based on Flooding Damage}

In previous studies, various resilience indices for urban drainage systems were suggested to determine system resilience in urban draining areas. Almost all of the resilience indices were calculated using flooding volume obtained by rainfall runoff simulations. As mentioned before, the resilience index is required to evaluate appropriate flooding damage in urban drainage systems because flooding volume is different from flooding damage. The comparison of the resilience index based on the flooding volume and flooding damage is shown in Figure 4.

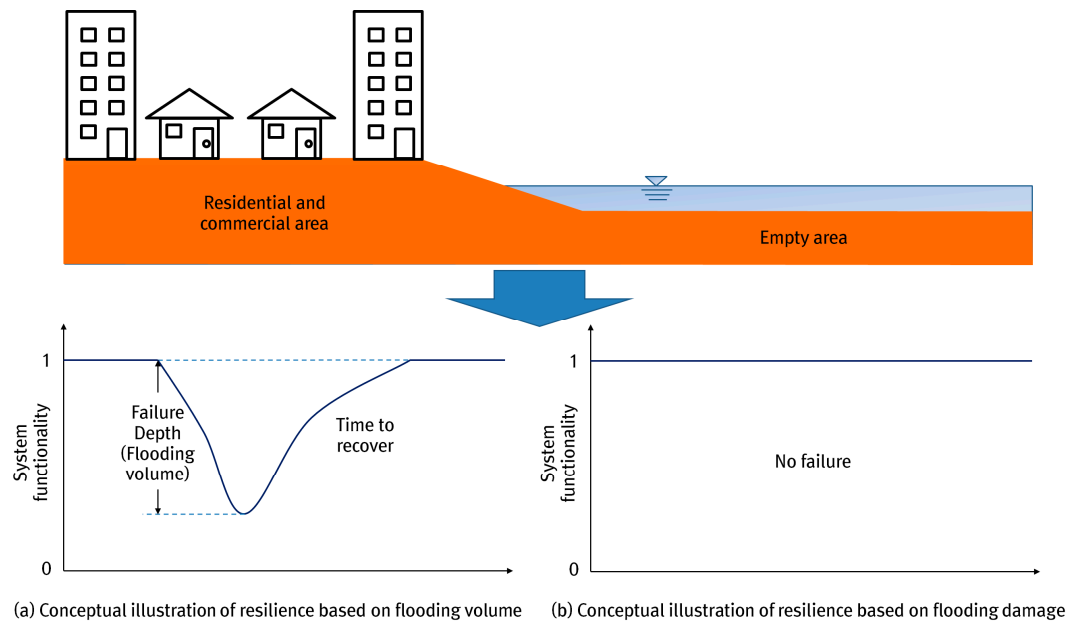

Figure 4. Comparison of resilience index based on flooding volume and flooding damage. (a) Conceptual illustration of resilience based on flooding volume; (b) Conceptual illustration of resilience based on flooding volume. 
Failure in Figure $4 \mathrm{~b}$ occurred if flooding also occurred in residential and commercial areas. Figure 4 shows the difference between resilience based on the flooding volume and flooding damage. In this study, the concept in Figure $4 \mathrm{~b}$ was applied to evaluate the system resilience in the target area. Utility performance in urban drainage systems should be able to show the status of urban drainage systems for each time. In this study, the status of urban drainage systems for various frequencies of rainfall compared to the extreme rainfall with 100-year frequency. Utility performance for each time can be calculated by Equation (6):

$$
u(T)_{i}=1-\frac{D_{i}}{D_{e}}
$$

where $u(T)_{i}$ represents the utility performance function at time $i, D_{i}$ represents the flooding damage (cost) based on selected rainfall data at time $i$, and $D_{e}$ is the flooding damage (cost) based on extreme rainfall data at time $i$. There are two requirements. The first requirement is that the rainfall durations $D_{i}$ and $D_{e}$ should be the same. The second requirement is that the frequency of $D_{e}$ should be higher than that of $D_{i}$. A high value of utility performance function means that the urban drainage system in the target watershed has the ability to resist system failure including flooding damage. The resilience based on flooding damage is calculated by the utility performance functions at each time. The resilience index showing the degree of resilience according to the flooding damage when rainfall events of each frequency occur by comparing flooding damage when extreme rainfall occurs. The resilience based on the flooding damage in urban drainage systems is calculated by Equation (7):

$$
R_{d}=\frac{1}{T} \int_{0}^{T} u(T) d T,
$$

where $R_{d}$ represents the resilience in urban drainage systems and $T$ is the total time rainfall runoff simulation. In this study, 15 rainfall events generated by the third quartile of the Huff distribution were used for calculation of resilience in the target urban drainage system. These 15 rainfall occurrences had durations of 30, 60, and $90 \mathrm{~min}$, and frequencies of 10,30, 50, 70, and 100 years. The rainfall data with the 100-year frequency was selected from among the five frequencies as extreme rainfall data. Other rainfall data with other frequencies was used for selected rainfall data.

\section{Applications and Results}

\subsection{Study Area}

Jeongup is an urbanized city of Jeollabuk-do province in Korea. Many apartments and buildings are located in Sintaein basin, Jeongup. The total drainage area of Sintaein basin is 67.9 ha. This area was inundated six times in ten years, from 2002 to 2011. In 2011, there was inundation by extreme rainfall over $400 \mathrm{~mm}$. The sewer network in Sintaein basin was constructed to simulate rainfall runoff. The sewer network in the drainage area, including 175 subcatchments and 175 conduits, is shown in Figure 5.

There are five subareas: A1 (17.6 ha), A2 (21.5 ha), A3 (0.7 ha), A4 (15.1 ha), and A5 (13.0 ha). A1 is upstream in the drainage area and is a residential area with schools and apartments. A2 is midstream in the drainage area and includes both residential and commercial areas. A3 consists of buildings and empty land. A4 is a commercial area including stations and churches. A4 is susceptible to inundation because it receives the discharge from $\mathrm{A} 1, \mathrm{~A} 2$, and $\mathrm{A} 3$. $\mathrm{A} 5$ is downstream in the drainage area and includes public facilities such as offices, post offices, and schools. 


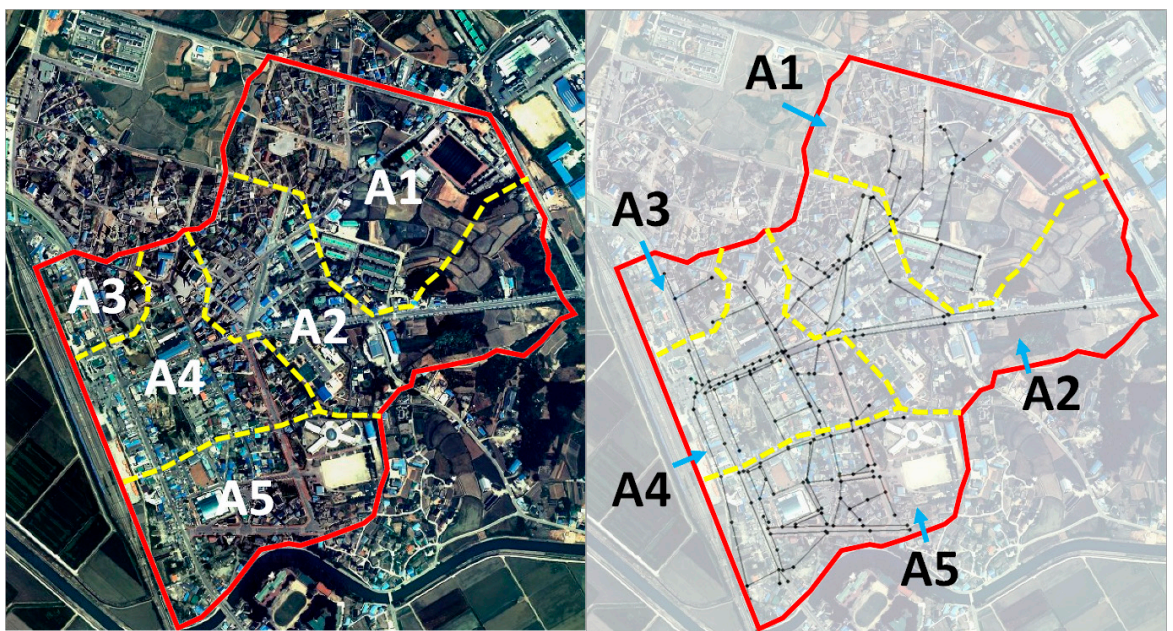

Figure 5. Sewer network in target area (from Google Earth Imagery @ , Google Inc.).

\subsection{Conversion from Flooding Volume to Flooding Damage}

The calculation of damage to human is excluded from this study because it is difficult to calculate and it is uncertain. The property value, the ratio of flooding area and the ratio of damage to flooding depth are required to calculate flooding damage. The first step is the calculation of the property value about each factor. In the property value of structures in residential areas, Table 5 shows the number of building types by subareas.

Table 5. The number of residence types by subareas.

\begin{tabular}{|c|c|c|c|c|c|}
\hline $\begin{array}{ll}\text { Types } & \text { Subareas }\end{array}$ & A1 & A2 & A3 & A4 & A5 \\
\hline Detached houses & 89 & 36 & 44 & 41 & 49 \\
\hline Apartments & 5 & 0 & 0 & 0 & 0 \\
\hline Buildings & 17 & 16 & 7 & 9 & 22 \\
\hline
\end{tabular}

The price per area of residence types in Table 6 is quoted from the data of Korea Appraisal Board [33]. Construction industry deflator is based on the data of Korea Development Institute [34]. The property value of structure in residential areas is calculated by multiplying the number of houses and building, price per area, number of floors and construction industry deflator in each subarea.

Table 6. The price per area of residence types.

\begin{tabular}{cccc}
\hline Types & Detached Houses & Apartments & Buildings \\
\hline Price per area $\left(\right.$ won $\left./ \mathrm{m}^{2}\right)$ & $1,385,000$ & $1,690,000$ & 853,000 \\
\hline
\end{tabular}

In the property value of contents in residential areas, assessment about the price of contents is calculated as the household appraisal value (12,182,399 won/household) for each household [33]. There is no agricultural area in the target watershed and the property value of the agricultural area is not calculated. For calculating the property value of industrial areas, the number of works in the target watershed is shown in Table 7. 
Table 7. The number of works in target watershed.

\begin{tabular}{lccccc}
\hline \multicolumn{1}{c}{ Subareas } & A1 & A2 & A3 & A4 & A5 \\
\hline Manufacturing industry & 0 & 0 & 0 & 0 & 0 \\
Electronic enterprise Gas and water utility & 0 & 3 & 1 & 4 & 1 \\
Waste water and environmental restoration & 0 & 0 & 0 & 1 & 0 \\
Construction industry & 0 & 0 & 0 & 2 & 0 \\
Wholesale business and retail trade & 13 & 18 & 4 & 24 & 38 \\
Transportation industry & 0 & 0 & 1 & 0 & 0 \\
Accommodation and restaurant business & 4 & 38 & 7 & 18 & 25 \\
Broadcasting and information industry & 0 & 2 & 0 & 2 & 0 \\
Financial and insurance business & 0 & 4 & 0 & 2 & 0 \\
Real estate industry & 0 & 1 & 0 & 2 & 0 \\
Science and technology services & 0 & 11 & 2 & 22 & 5 \\
Business facilities management and & 0 & 0 & 0 & 0 & 1 \\
business support services & 0 & 1 & 0 & 2 & 0 \\
Public administration & 0 & 3 & 0 & 1 & 3 \\
Educational services industry & 0 & 10 & 2 & 8 & 3 \\
Health care and social welfare & 0 & 8 & 2 & 6 & 3 \\
Art and leisure service & 1 & 3 & 0 & 1 & 1 \\
Association and private service & & & & 2 \\
\hline
\end{tabular}

Total property value of all subareas including residential and industrial area is shown in Table 8 . There is no property value of agricultural values in all subareas because there is no agricultural area in all subareas.

Table 8. The results of property value of subareas.

\begin{tabular}{cccccc}
\hline Subareas & A1 & A2 & A3 & A4 & A5 \\
\hline Property value of structure (won) & $8,908,320,000$ & $2,505,465,000$ & $1,855,900,000$ & $3,711,800,000$ & $2,041,490,000$ \\
Property value of contents (won) & $755,308,738$ & $328,924,773$ & $243,647,980$ & $487,295,960$ & $268,012,778$ \\
Property value of tangible assets (won) & $19,293,116$ & $710,845,218$ & $225,385,429$ & $937,125,269$ & $276,831,416$ \\
Property value of inventories (won) & $7,200,137$ & $18,552,083$ & $4,331,518$ & $26,725,653$ & $23,541,351$ \\
Total property value (won) & $9,690,121,991$ & $3,563,787,074$ & $2,329,264,927$ & $5,162,946,882$ & $2,609,875,545$ \\
Area (m ${ }^{2}$ ) & 184,100 & 114,190 & 7,430 & 125,310 & 71,060 \\
Property value per area (won $/ \mathrm{m}^{2}$ ) & 52,635 & 31,209 & 313,495 & 14,201 & 36,728 \\
\hline
\end{tabular}

Synthetic rainfall data generated by the third quartile of Huff distribution is used as input data to obtain the flooding area through SWMM simulations. Flooding areas when the total amount of synthetic rainfall is $80 \mathrm{~mm}$ and $150 \mathrm{~mm}$ among various results are shown in Figure 6.

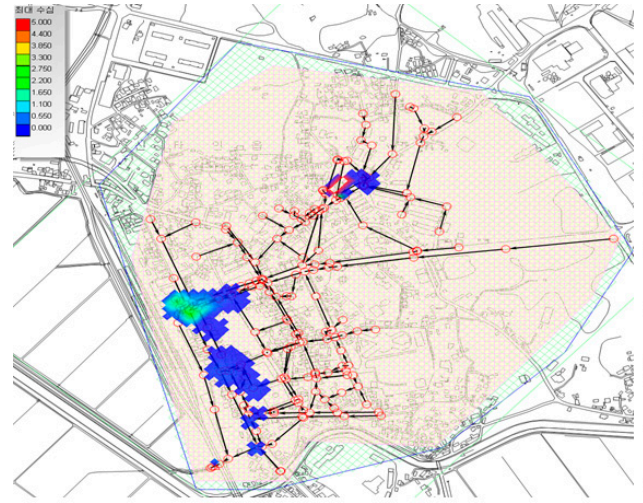

(a) $80 \mathrm{~mm}$

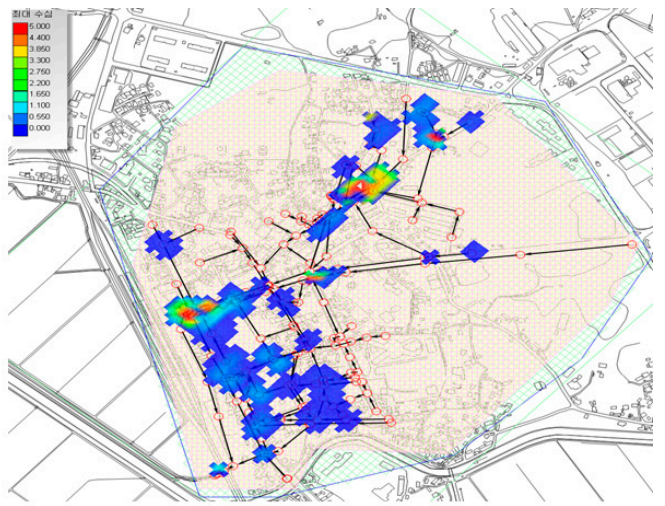

(b) $150 \mathrm{~mm}$

Figure 6. Flooding areas. 
In a previous study, damage functions between flooding damage and flooding volume were calculated [35]. Damage functions between flooding volume and flooding damage were obtained by MD-FDA [35]. The type of damage functions was the sifting power function. In this study, the same damage functions were used for conversion from flooding volume to flooding damage. Damage functions in each subarea are shown in Equations (8)-(12). These are the damage functions for A1, A2, A3, A4, and A5, respectively:

$$
\begin{gathered}
D=1.107 \times 10^{6} \times(V-63.9)^{0.46012}, \\
D=5.927 \times 10^{5} \times(V)^{0.44332}, \\
D=1.331 \times 10^{7} \times(V-291.5)^{0.25969}, \\
D=4.074 \times 10^{5} \times(V)^{0.5774}, \\
D=3.549 \times 10^{4} \times(V)^{0.9496,}
\end{gathered}
$$

where $D$ is the flooding damage and $V$ is the flooding volume in urban drainage systems. Rainfall runoff simulations for obtaining the flooding volume were conducted using SWMM [36]. The results of minutely flooding volume were converted to minutely flooding damage by damage functions. The conversion process from flooding volume to flooding damage is shown in Figure 7.
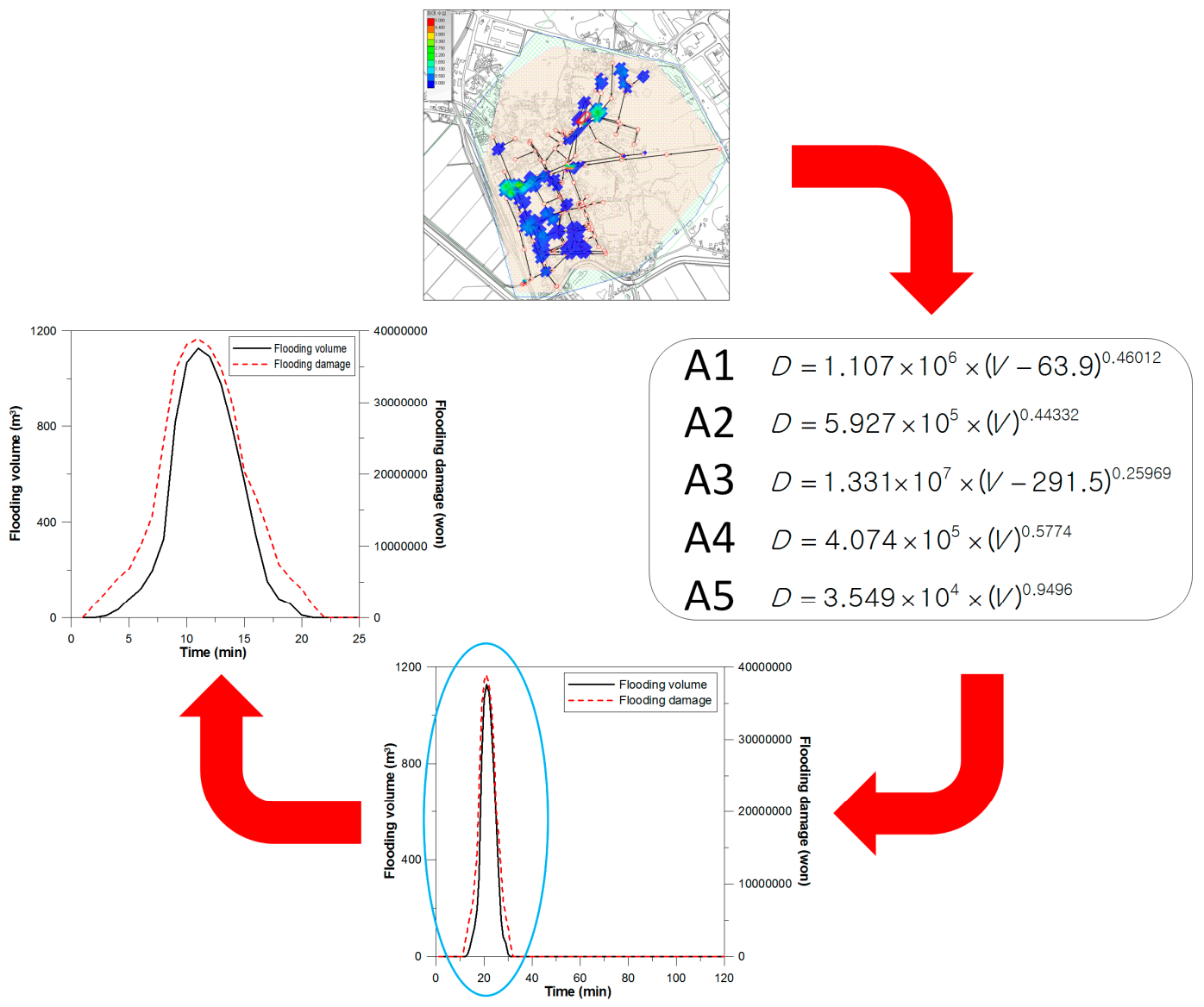

Figure 7. Conversion process from flooding volume to flooding damage.

\subsection{Resilience Based on Flooding Damage}

In this study, 100-year frequency rainfall was selected as the extreme rainfall for the application of the resilience index. The result of resilience in the target area is shown in Table 9. 
Table 9. The result of resilience in the target area.

\begin{tabular}{ccccc}
\hline \hline Frequency (Years) & \multirow{2}{*}{$\mathbf{1 0}$} & $\mathbf{3 0}$ & $\mathbf{5 0}$ & $\mathbf{7 0}$ \\
\hline Duration (Minutes) & & & & \\
\hline $\mathbf{3 0}$ & 0.933741 & 0.895701 & 0.876585 & 0.860621 \\
$\mathbf{6 0}$ & 0.932841 & 0.868809 & 0.839358 & 0.826333 \\
$\mathbf{9 0}$ & 0.924555 & 0.851202 & 0.813135 & 0.797292 \\
\hline
\end{tabular}

As frequency increases, the resilience in the urban drainage system decreases. As duration increases, the resilience in the urban drainage system decreases. This means that this drainage system has low resilience when rainfall occurs with a high frequency and for a long duration. The values of resilience and time are shown in Figures 8-10.

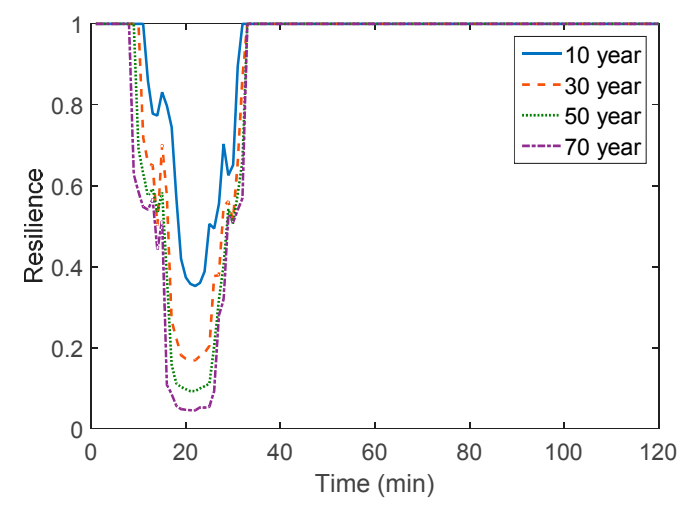

Figure 8. Variance of resilience at 30-min duration.

In Figure 8, the value of resilience is lowest at about $20 \mathrm{~min}$ in all frequencies including 10, 30, 50 , and 70 years. After $40 \mathrm{~min}$, the resilience returned to one in all cases. As frequency increases, the resilience in the urban drainage system decreases. Flooding occurs when rainfall occurs with a 10-year frequency because the design frequency of the sewer network in the target area is 10 years. Failure (flooding damage) duration for all frequencies is similar. The reason is that the time of concentration in the target area is $20 \mathrm{~min}$ and the amount of rainfall in the target area is drained rapidly. The result of the resilience goes down to 0.4 in 10-year frequency and to below 0.2 in 30-year frequency. The result of resilience goes down to 0.1 in 50-year frequency and to below 0.1 in 70-year frequency. This result means that the area is susceptible when rainfall occurs for a short duration and in large amounts.

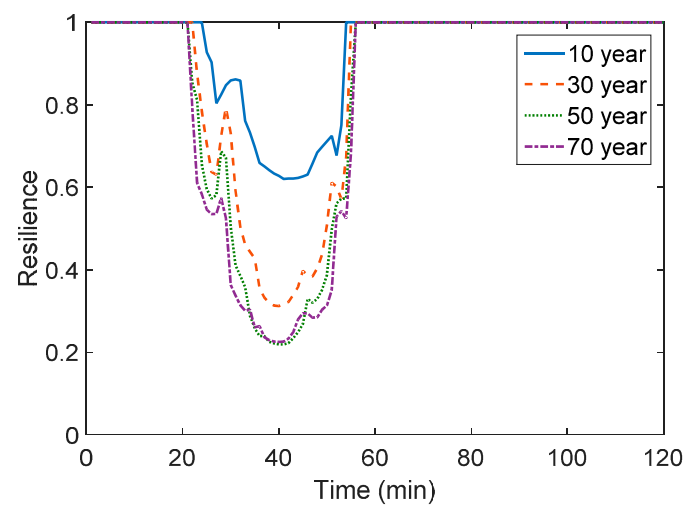

Figure 9. Variance of resilience at 60-min duration. 
In Figure 9, the value of resilience is lowest at about $40 \mathrm{~min}$ in all frequencies including 10, 30, 50, and 70 years. After $60 \mathrm{~min}$, the resilience returned to one in all cases. Although the shape of the graph for the 60-min duration is similar to that for $30 \mathrm{~min}$, it spreads significantly to the left and right in the graph for the 60-min duration. Generally, the lowest value in the 60-min duration is higher than that in the 30-min duration, though the resilience in the urban drainage system decreases as frequency increases. The result of resilience goes down to 0.6 in a 10-year frequency and to 0.3 in a 30 -year frequency. The results of resilience in a 50-year frequency and a 70-year frequency go down to 0.2. This result means that the area is better able to withstand rainfall of 60-min duration than rainfall of 30-min duration. The resilience in this area, with rainfall occurring at a frequency of over 10-years, goes down dramatically. The results of resilience with rainfall occurring at 50- and 70-year frequencies are similar, which means that the increase in the amount of rainfall from a 50-year frequency to a 70-year frequency will not result in additional flooding damage.

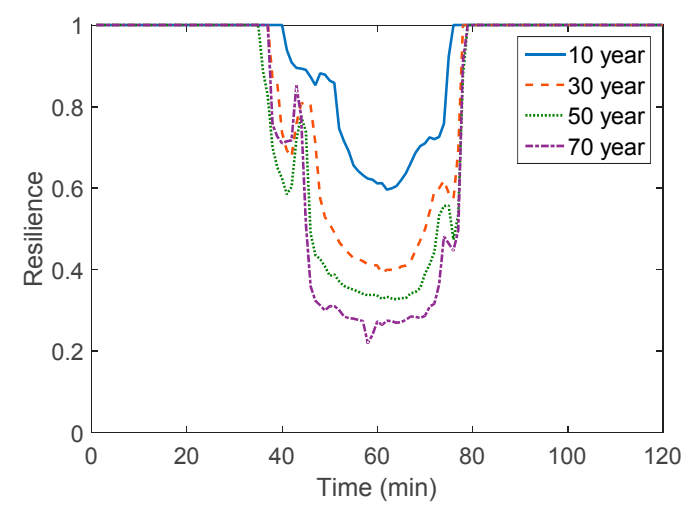

Figure 10. Variance of resilience at 90-min duration.

In Figure 10, the value of resilience is lowest at about $60 \mathrm{~min}$ in all frequencies including 10, 30, 50, and 70 years. After $80 \mathrm{~min}$, the resilience returned to one in all cases. Although the shape of the graph for the 90-min duration is similar to that for $30 \mathrm{~min}$ and $60 \mathrm{~min}$, it spreads most widely to the left and right in the graph for the 90-min duration. Generally, the lowest value in the 90-min duration is higher than that in the 30-min duration and similar to that in the 60-min duration. The result of resilience goes down to 0.6 in 10-year frequency and to 0.4 in 30-year frequency. The result of resilience goes down to 0.3 in 50 -year frequency and to 0.2 in 70 -year frequency. This result means that the area is better able to withstand rainfall of 90-min duration than rainfall of 30- and 60-min duration. The resilience in this area, with rainfall occurring at a frequency of over 10 years, goes below 0.5 because of the design frequency of the sewer network in the target area.

\section{Conclusions}

In urban drainage systems, flooding damage can pose a critical threat to human life. In the process of making flooding control plans, it will be useful to have a resilience index based on flooding damage. Flooding volume in subareas is different from flooding damage in subareas because some subareas are immediately damaged by a certain amount of flooding while other subareas are not. A new resilience index based on flooding damage has been suggested.

Multi-dimensional flood damage analysis has been selected to obtain the flooding damage in each subarea. Sintaein basin in Jeongup, Korea, has been selected as a target area. Sintaein basin is divided into five subareas, namely, A1, A2, A3, A4, and A5, according to land use. In subareas of the target area suggested in the previous study, damage functions were used for the conversion from flooding volume to flooding damage [32]. To obtain the results of flooding volume, the SWMM was used in rainfall runoff simulations. 
Synthetic data for rainfall runoff simulations was distributed using the Huff distribution [30]. The Huff distribution is generally used for the design of drainage facilities in Korea. The third quartile of the Huff distribution was selected because it was appropriate for application in Korea [32]. Fifteen rainfall events had durations of 30,60, and $90 \mathrm{~min}$ and frequencies of 10, 30, 50, 70, and 100 years, generated by the third quartile of the Huff distribution, which were used for the calculation of resilience in the target area.

The results of flooding volume were converted into the results of flooding damage by damage functions after obtaining the results of flooding volume in each subarea by simulating SWMM. The flooding damage in each subarea was used to calculate the utility performance per minute. The results of the utility performance in each subarea were combined with the results of the utility performance in the target area. The resilience in the target area was calculated by the results of the utility performance. The rainfall events with 100 -year frequency were selected because the calculation of resilience requires the determination of extreme rainfall. The resilience decrease as the duration decreased because rainfall events with short duration burden urban drainage systems.

In 30-min duration, the resilience go down at about 10-min and rise up at about 40-min. The result of the resilience in 30-min goes down to 0.4 in 10-year frequency and to below 0.2 in 30-year frequency. The results of the resilience go down to 0.1 in 50-year frequency and to below 0.1 in 70-year frequency. In 60-min duration, the resilience goes down at about 20-min and rises up at 50-min. The results of the resilience in 60-min go down to 0.6 in 10-year frequency and to 0.3 in 30-year frequency. The results of resilience in 50-year frequency and 70-year frequency go down to 0.2 . In 90-min duration, the resilience goes down at $30 \mathrm{~min}$ and rises up at $80-\mathrm{min}$. The results of resilience go down to 0.6 in 10 -year frequency and to 0.4 in 30-year frequency. The results of resilience go down to 0.3 in 50 -year frequency and to 0.2 in 70-year frequency.

In this study, the contents of uncertainty and vulnerability in socioeconomic and physical aspects were not included in estimating flooding damage. Future studies would yield more detailed results if there were uncertainty and vulnerability in socioeconomic and physical aspects. This study excluded the damage to humans and did not consider the total damage of urban areas because there are resident and floating people in urban areas. Age and gender in the damage to humans should be considered. The resilience index based on flooding damage can be used for the evaluation of flood control plans such the installation, replacement, and rehabilitation of drainage facilities. Resilience index can be used as a fundamental indicator for the regional evaluation considering the flooding damage. Because various structural measures such as installation of new pump stations and detention reservoirs and replacement and rehabilitation of sewer conduits need to be evaluated, the resilience index based on flooding damage will support decision making in flood control plans. In future research, the resilience index based on flooding damage will be simplified by reports and recorded data.

Acknowledgments: This research was supported by a grant (13AWMP-B066744-01) from the Advanced Water Management Research Program funded by the Ministry of Land, Infrastructure, and Transport of the Korean government and The National Research Foundation (NRF) of Korea, funded by the Korean government (MSIP) (No. 2016R1A2A1A05005306).

Author Contributions: Eui Hoon Lee carried out the survey of previous studies and wrote the draft of the manuscript. Eui Hoon Lee revised the draft until the final version of the manuscript and simulated the inlet/outlet operation. Eui Hoon Lee and Joong Hoon Kim conceived the original idea of the proposed method.

Conflicts of Interest: The authors declare no conflict of interest.

\section{References}

1. Haughton, G. Developing sustainable urban development models. Cities 1997, 14, 189-195. [CrossRef]

2. Chiesura, A. The role of urban parks for the sustainable city. Landsc. Urban Plan. 2004, 68, 129-138. [CrossRef]

3. Pickett, S.T.; Cadenasso, M.L.; Grove, J.M. Resilient cities: Meaning, models, and metaphor for integrating the ecological, socio-economic, and planning realms. Landsc. Urban Plan. 2004, 69, 369-384. [CrossRef]

4. Egger, S. Determining a sustainable city model. Environ. Model. Softw. 2006, 21, 1235-1246. [CrossRef] 
5. Blackmore, J.M.; Plant, R.A. Risk and resilience to enhance sustainability with application to urban water systems. J. Water Resour. Plan. Manag. 2008, 134, 224-233. [CrossRef]

6. Coaffee, J. Risk, resilience, and environmentally sustainable cities. Energy Policy 2008, 36, 4633-4638. [CrossRef]

7. Ahern, J. From fail-safe to safe-to-fail: Sustainability and resilience in the new urban world. Landsc. Urban Plan. 2011, 100, 341-343. [CrossRef]

8. Djordjević, S.; Butler, D.; Gourbesville, P.; Mark, O.; Pasche, E. New policies to deal with climate change and other drivers impacting on resilience to flooding in urban areas: The CORFU approach. Environ. Sci. Policy 2011, 14, 864-873. [CrossRef]

9. Park, J.; Seager, T.P.; Rao, P.S.C. Lessons in risk-versus resilience-based design and management. Integr. Environ. Assess. Manag. 2011, 7, 396-399. [CrossRef] [PubMed]

10. Lansey, K. Sustainable, robust, resilient, water distribution systems. In Proceedings of the 14th Water Distribution Systems Analysis Conference (WDSA 2012), Adelaide, South Australia, 24-27 September 2012; Engineers Australia: Adelaide, Australia, 2012; p. 1.

11. Desouza, K.C.; Flanery, T.H. Designing, planning, and managing resilient cities: A conceptual framework. Cities 2013, 35, 89-99. [CrossRef]

12. Jabareen, Y. Planning the resilient city: Concepts and strategies for coping with climate change and environmental risk. Cities 2013, 31, 220-229.

13. Park, J.; Seager, T.P.; Rao, P.S.C.; Convertino, M.; Linkov, I. Integrating risk and resilience approaches to catastrophe management in engineering systems. Risk Anal. 2013, 33, 356-367. [PubMed]

14. Butler, D.; Farmani, R.; Fu, G.; Ward, S.; Diao, K.; Astaraie-Imani, M. A new approach to urban water management: Safe and SuRe. Procedia Eng. 2014, 89, 347-354.

15. Hwang, H.; Lansey, K.; Quintanar, D.R. Resilience-based failure mode effects and criticality analysis for regional water supply system. J. Hydroinform. 2015, 17, 193-210.

16. Mugume, S.N.; Gomez, D.E.; Fu, G.; Farmani, R.; Butler, D. A global analysis approach for investigating structural resilience in urban drainage systems. Water Res. 2015, 81, 15-26. [PubMed]

17. Siekmann, T.; Siekmann, M. Resilient urban drainage-Options of an optimized area-management. Urban Water J. 2015, 12, 44-51.

18. Kotzee, I.; Reyers, B. Piloting a social-ecological index for measuring flood resilience: A composite index approach. Ecol. Indic. 2016, 60, 45-53.

19. Mugume, S.N.; Melville-Shreeve, P.; Gomez, D.; Butler, D. Multifunctional urban flood resilience enhancement strategies. Proc. Inst. Civ. Eng. Water Manag. 2017, 170, 115-127.

20. Mugume, S.N.; Butler, D. Evaluation of functional resilience in urban drainage and flood management systems using a global analysis approach. Urban Water J. 2016, 1-10. [CrossRef]

21. Lee, E.H.; Lee, Y.S.; Joo, J.G.; Jung, D.; Kim, J.H. Flood Reduction in Urban Drainage Systems: Cooperative Operation of Centralized and Decentralized Reservoirs. Water 2016, 8, 469.

22. Gupta, K. Urban flood resilience planning and management and lessons for the future: A case study of Mumbai, India. Urban Water J. 2007, 4, 183-194. [CrossRef]

23. White, I. The absorbent city: Urban form and flood risk management. Proc. Inst. Civ. Eng.-Urban Des. Plan. 2008, 161, 151-161. [CrossRef]

24. Barroca, B.; Bernardara, P.; Mouchel, J.M.; Hubert, G. Indicators for identification of urban flooding vulnerability. Nat. Hazards Earth Syst. Sci. 2006, 6, 553-561. [CrossRef]

25. Van Herk, S.; Zevenbergen, C.; Ashley, R.; Rijke, J. Learning and Action Alliances for the integration of flood risk management into urban planning: A new framework from empirical evidence from The Netherlands. Environ. Sci. Policy 2011, 14, 543-554. [CrossRef]

26. Lamond, J.E.; Proverbs, D.G. Resilience to flooding: Lessons from international comparison. Proc. Inst. Civ. Eng.-Urban Des. Plan. 2009, 162, 63-70. [CrossRef]

27. Choi, S.A.; Yi, C.S.; Shim, M.P.; Kim, H.S. Multi-Dimensional Flood Damage Analysis (I): Principle and Procedure. J. Korea Water Resour. Assoc. 2006, 50, 1-9.

28. Study on Economical Analysis Method of Flood Control Project; Ministry of Construction and Transportation: Seoul, Korea, 2004.

29. Statistics Korea. Available online: kostat.go.kr (accessed on 25 February 2017).

30. Huff, F.A. Time distribution of rainfall in heavy storms. Water Resour. Res. 1967, 3, 1007-1019. [CrossRef] 
31. Korea Precipitation Frequency Data Server. Available online: www.k-idf.re.kr (accessed on 27 February 2017).

32. Yoon, Y.N.; Jung, J.H.; Ryu, J.H. Introduction of design flood estimation. J. Korea Water Resour. Assoc. 2013, $46,55-68$.

33. Korea Appraisal Board. Available online: www.kab.co.kr (accessed on 22 February 2017).

34. Korea Development Institute. Available online: www.kdi.re.kr (accessed on 3 March 2017).

35. Choi, H.; Lee, E.H.; Joo, J.G.; Kim, J.H. Determining optimal locations for rainwater storage sites with the goal of reducing urban inundation damage costs. KSCE J. Civ. Eng. 2016, 1-13. [CrossRef]

36. United States Environmental Protection Agency (USEPA). Storm Water Management Model User's Manual Version 5.0; EPA: Washington, DC, USA, 2010.

2017 by the authors. Licensee MDPI, Basel, Switzerland. This article is an open access article distributed under the terms and conditions of the Creative Commons Attribution (CC BY) license (http://creativecommons.org/licenses/by/4.0/). 